\title{
Intra- and inter-observer concordance of the stabilizing chains test and its relationships with measures on a force platform
}

\author{
Orlando Conde Vázquez', Carlos Mohíno Fernández²
}

\begin{abstract}
Background: There are numerous manual tests that are part of the daily work of clinicians, in order to assist in the diagnosis to a subsequent therapeutic approach. Objectives: The stabilizing chains* test was chosen to study its intra- and inter-observer reproducibility in 24 children with 11 years old, and the possible relation with certain baropodometric variables. Methods: The test data were collected by 2 operators and the baropodometric variables by a force platform. Cohen's Kappa coefficient and Student's t-tests were performed. Results: The results showed a good kappa coefficient (0.497 - 0.746) in the intra-observer and poor to moderate in the inter-observer (0.083 - 0.438). There are also relationships to the weight percentage in the frontal and sagittal planes $(p \leq 0.05)$. Conclusion: These results give validity to use the test in daily practice. ${ }^{*}$ The English denomination of the test is a literal translation of the French expression 'chaînes stabilisatrices'.
\end{abstract}

Keywords: Reproducibility of results; Postural balance; Physiology; Physical Examination; Manual Therapy.

\section{INTRODUCTION}

There is currently a high demand for therapeutic approach through manual therapy in the treatment of various musculoskeletal pathologies and its application is highly recommended compared to other medical interventions $s^{(1,2)}$. In order to achieve good results, diagnostics must be accurate and clinicians must have suitable technics to get it. Unfortunately, a vast majority of manual tests lack good reliability and validity ${ }^{(3-6)}$, although pain palpation looks to be better ${ }^{(7)}$, and that makes difficult the understanding between therapists and decreases therapeutic possibilities. In this field, difficulties regarding a gold standard or objective comparisons between operators are the barriers to the development.

The study of the human postural control system seems to be of capital importance in several processes related to health. In that way, it is actually considered regarding pain ${ }^{(8,9)}$, respiration ${ }^{(10)}$, mobility ${ }^{(11)}$ and even cognitive functions ${ }^{(12)}$. Therefore, valid tests of the postural control system will be helpful in daily practice.

The aim of this study was to evaluate the reproducibility of the stabilizing chains test (SCT) described by Villeneuve and Parpay ${ }^{(13)}$ as a part of its validity, and develop its possible application in the field of posturology knowing the professional technics used on it. Likewise, we explore the relationship of force platform variables and the results of the operators, since there are no studies in this sense done with school-aged children.

\section{METHODS}

\section{Subjects}

Data were collected from 24 children, 11 of them male and 13 female, with 11-12 years old. We were interested in the last course of primary school due to physiology of posture control system, realizing that stability is mature over 10 years old ${ }^{(14)}$. Inclusion criteria were to accept the trial, with informed and signed consent of the parents or legal guardians of the minor, which included the acceptance for publication of patient data; be able to correctly follow the orders of the operators and absence of any physical or mental impairment that could alter a priori the motor behaviour on upright or one-leg standing positions. The study was approved by the Research Ethics Committee at Galicia (2018/281) and was conducted in the

Corresponding Author: Orlando Conde Vázquez, Travesía do Restollal, 1-A, baixo; Zip code: 15702; Santiago de Compostela, A Coruña, Spain; Telephone: +34 657120828. E-mail: orlando.conde@rai.usc.es

${ }^{1}$ Departamento de Ciências Morfológicas, Universidade de Santiago da Compostela, A Coruña, Espanã.

Full list of author information is available at the end of the article.

Financial support: None.

Submission date 28 February 2018; Acceptance date 03 July 2018; Publication date 16 October 2018 
Children and Primary School "Cañada Real" of Malagón, Ciudad Real, Spain; in accordance with the declaration of Helsinki.

\section{Procedures}

The study design was divided into two phases. The first is a concordance study, in which the group underwent the SCT by two different operators; and the second is an analytical study, in which children performed a force platform test in standing position in order to acquire the baropodometric variables.

Children performed the stabilizing chains test as first described by their authors ${ }^{(13)}$. All the children went through both operators twice in random order, and results were noted as physiological (elevation) or non-physiological (no-elevation/descent) of the posterior-superior iliac spine on the tested side. The tests were made and noted on the right and left lower limbs of the children, and independently of the side of the trial a global-test result was also noted (physiological = both sides tested as physiological; otherwise $=$ non-physiological).

It was used a force platform with specific software to acquire the baropodometric data (Loran Engineering, Castel Maggiore, Bologna, Italy; SKG Software). Children were recorded immediately after each SCT during 30 seconds, $4 \mathrm{~cm}$ of separation between heels and forming a 30 은 degrees angle between feet. All tests were conducted in eyes-closed condition and cotton rolls between posterior teeth. The parameters evaluated were the weight percentages in the frontal and sagittal planes.

\section{Statistical analysis}

The intra- and inter-observer agreement of the operators were analysed by the Cohen's kappa statistic ${ }^{(15)}$ and the relationship with baropodometric measures using a Student's t-test comparison, with a significance level of $5 \%$ for the analysis. All statistical analysis was performed using IBM SPSS v21.0 (IBM Corporation, Armonk, NY, USA).

\section{RESULTS}

Table 1 shows the Cohen's kappa coefficient ( $\mathrm{k}$ ) for the two operators, with $95 \%$ confidence intervals and concordance percentages. The Cohen's kappa ranges for inter-observer were from 0.083 to 0.438 , which means insignificant to moderate degree of agreement according to the scale referred by Landis and $\mathrm{Koch}^{(16)}$. Intra-observer agreement was higher in both operators, ranging from 0.647 to 0.746 , which implies a substantial agreement.

None of the force platform variables measured after test 1 were significant (table 2). Nevertheless, an increase to the right side weight percentage was significant regarding the second test of the second operator $(t=-2.260 ; p=0.034)$. Those declared as physiological on SCT 2 increased the load percentage to the right side.

Table 1. Inter- and intra-observer agreement and percentages of concordance.

\begin{tabular}{|c|c|c|c|c|}
\hline & $\mathbf{K}$ & $95 \% \mathrm{Cl}$ & $Z_{\mathrm{k}}$ & $\%$ Concordance \\
\hline \multicolumn{5}{|c|}{ Inter-observer } \\
\hline \multicolumn{5}{|c|}{ Stabilizing chains test 1} \\
\hline Right & 0.083 & $(-0.314 ; 0.480)$ & 0.408 & 54.2 \\
\hline Left & 0.211 & $(-0.126 ; 0.548)$ & 1.226 & 58.3 \\
\hline Global & 0.217 & $(-0.177 ; 0.610)$ & 1.079 & 62.5 \\
\hline \multicolumn{5}{|c|}{ Stabilizing chains test 2} \\
\hline Right & 0.250 & $(-0.136 ; 0.636)$ & 1.270 & 62.5 \\
\hline Left & 0.270 & $(-0.078 ; 0.618)$ & 1.516 & 62.5 \\
\hline Global & 0.438 & $(0.057 ; 0.818)$ & 2.257 & 75 \\
\hline \multicolumn{5}{|c|}{ Intra-observer } \\
\hline \multicolumn{5}{|l|}{$1-1$} \\
\hline Right & 0.667 & $(0.369 ; 0.964)$ & 4.388 & 83.4 \\
\hline Left & 0.746 & $(0.479 ; 1.012)$ & 5.485 & 87.5 \\
\hline Global & 0.647 & $(0.337 ; 0.956)$ & 4.095 & 83.4 \\
\hline \multicolumn{5}{|l|}{$2-2$} \\
\hline Right & 0.497 & $(0.148 ; 0.845)$ & 2.792 & 75 \\
\hline Left & 0.625 & $(0.291 ; 0.958)$ & 3.676 & 83.3 \\
\hline Global & 0.727 & $(0.440 ; 1.013)$ & 4.980 & 87.5 \\
\hline
\end{tabular}

Note: $Z_{k}$ : significance level; $\alpha$-value $=0.05 .95 \% \mathrm{Cl}$ : confidence intervals 
Table 2. Student's t-test values of weight load percentage.

\begin{tabular}{lccc}
\hline & & $\mathbf{t}_{\text {\%AW }}$ & $\mathbf{t}_{\text {\%RW }}$ \\
\hline Operator 1 & SCT 1 & & \\
& Right & -0.145 & -0.385 \\
& Left & 0.067 & 0.166 \\
& SCT 2 & & \\
& Right & -0.040 & -1.619 \\
Operator 2 & Left & -0.238 & -0.410 \\
& SCT 1 & & \\
& Right & 0.431 & -1.310 \\
& Left & -1.044 & -0.305 \\
& SCT 2 & & \\
& Right & 0.636 & $-\mathbf{2 . 2 5 2 *}$ \\
& Left & 0.783 & -0.478 \\
\hline
\end{tabular}

Note: SCT: Stabilizing chains test. AW: Anterior weight. RW: rightward weight. ${ }^{*} p \leq 0.05$

Table 3. Student's t-test values regarding the change in the SCT results.

\begin{tabular}{lccc}
\hline & SCT 1 $\neq$ SCT 2 & $\mathbf{t}_{\text {\%AW }}$ & $\mathbf{t}_{\% \mathrm{RW}}$ \\
\hline Operator 1 & Right & 0.701 & -1.404 \\
& Left & $7.094^{*}$ & $6.540^{*}$ \\
Operator 2 & Right & 0.621 & -0.898 \\
& Left & 1.097 & 0.463 \\
\hline
\end{tabular}

Note:* $p \leq 0.05$

Interestingly, when the group studied is divided regarding the change in the SCT result, significant differences appear on the outcomes of the operator 1 (table 3 ). Subjects who changed from physiological to non-physiological (or vice versa) on the left side-test altered their anterior and lateral weight percentages $(t=7.094 ; p=0.019$ and $t=6.540$; $p=0.023$, respectively). In both cases they decreased the load percentages, forward and rightward.

\section{DISCUSSION}

Taking into account these results, the concordance study of SCT obtains an insignificant to discrete degree of inter-observer agreement, so it is not totally valid in the discourse among professionals. However, it reaches a good qualification in the intra-observer measurement, ranging from moderate to substantial agreement, providing a useful tool to explore the human postural control system in children.

Similar outcomes are exposed by Nguyen et al. ${ }^{(17)}$, showing a concordance percentage of $78 \%$ among 3 operators and greater than $85 \%$ by binomial. Broise and Geronimi ${ }^{(18)}$ showed good intra-observer concordance but significant differences in the inter-observer analysis, through the study of 16 healthy adults evaluated by 3 different clinicians.

None of the authors present a Cohen's kappa coefficient, which in our opinion brings more precision to the study because it takes into account the agreement's degree that happens by chance.

The results of the tests regarding weight percentages in the frontal and sagittal planes induce us to think about a momentary change in the motor scheme of the subject. Indeed, Blaszczyk and colleagues ${ }^{(19)}$ observe this strategy as a common form of being ready to recover unbalance. Several authors have found a direct linkage between asymmetrical loading on standing position and the movement of the centre of pressure on a force platform ${ }^{(20,21)}$, and mechanical task constraints contribute to this find ${ }^{(22)}$ but explanations about the relationships among weight bearing, muscle energy expended, stiffness and manual tests remain unclear.

\section{CONCLUSION}

Despite the extensive use of certain manual tests, including the SCT, operator-dependent manoeuvres should be interpreted carefully, as they lack the proper validity and reliability. Its application must be methodical and homogeneous, what implies a good training regarding factors as position of patient and clinician, depth of palpation, time and possible events that may appear. In the other hand, the SCT shows a good intra-tester agreement, so it may assist the posturological diagnosis added to other tests. Other trials can help if possible comparing to a gold standard or objectified results (through devices) to reinforce validity and reliability.

There is still a way to go, but the mere possibility that manual tests are able to pick up a change in the postural strategy has a great value, since they have a minimum cost and a considerable ease in its use. It would be really interesting to realize those variations in a clinical environment and relate them to other factors that may influence in postural control; new studies in that direction should be done.

\section{ACKNOWLEDGEMENTS}

Thanks to the management team of the Children and Primary School "Cañada Real" of Malagón, Ciudad Real, Spain.

\section{AUTHORS' CONTRIBUTIONS}

OCV and CMF designed the study and contributed to acquisition and interpretation of the data. OCV performed statistical analysis and drafted the manuscript. Both authors read and approved the final manuscript.

\section{CONFLICT OF INTEREST}

The authors declare that there was no conflict of interest.

\section{AUTHORS DETAILS}

${ }^{2}$ Ciudad Real, Castilla-La Mancha, España.

\section{REFERENCES}

1. Gellhorn AC, Chan L, Martin B, Friedly J. Management Patterns in Acute Low Back Pain: The Role of Physical Therapy. Spine. 2012; 37(9): 775-82.

2. Delitto A, George SZ, Van Dillen L, Whitman JM, Sowa G, Shekelle P, et al. Low Back Pain: Clinical Practice Guidelines Linked to the International 
Classification of Functioning, Disability, and Health from the Orthopaedic Section of the American Physical Therapy Association. J Orthop Sports Phys Ther. 2012; 42(4): A1-57.

3. Hestœk L, Leboeuf-Yde C. Are chiropractic tests for the lumbo-pelvic spine reliable and valid? A systematic critical literature review. J Manipulative Physiol Ther. 2000; 23(4): 258-75.

4. Vincent-Smith B, Gibbons P. Inter-examiner and intra-examiner reliability of the standing flexion test. Man Ther. 1999; 4(2): 87-93.

5. Holmgren $U$, Waling K. Inter-examiner reliability of four static palpation tests used for assessing pelvic dysfunction. Man Ther. 2008; 13(1): 50-6.

6. Haneline MT, Young M. A Review of Intraexaminer and Interexaminer Reliability of Static Spinal Palpation: A Literature Synthesis. J Manipulative Physiol Ther. 2009; 32(5): 379-86.

7. Stochkendahl MJ, Christensen HW, Hartvigsen J, Vach W, Haas M, Hestbaek $L$, et al. Manual Examination of the Spine: A Systematic Critical Literature Review of Reproducibility. J Manipulative Physiol Ther. 2006; 29(6): 475485.e10.

8. Ruhe A, Fejer R, Walker B. Is there a relationship between pain intensity and postural sway in patients with non-specific low back pain? BMC Musculoskelet Disord. 2011; 12(1): 162.

9. Mazaheri $\mathrm{M}$, Coenen $\mathrm{P}$, Parnianpour $\mathrm{M}$, Kiers $\mathrm{H}$, van Dieën JH. Low back pain and postural sway during quiet standing with and without sensory manipulation: A systematic review. Gait Posture. 2013; 37(1): 12-22.

10. Hodges PW, Gurfinkel VS, Brumagne S, Smith TC, Cordo PC. Coexistence of stability and mobility in postural control: evidence from postural compensation for respiration. Exp Brain Res. 2002; 144(3): 293-302.

11. Hamaoui A, Do M, Bouisset S. Postural sway increase in low back pain subjects is not related to reduced spine range of motion. Neurosci Lett. 2004; 357(2): 135-8.
12. Shanbehzadeh S, Salavati M, Talebian S, Khademi-Kalantari K, Tavahomi $M$. Attention demands of postural control in non-specific chronic low back pain subjects with low and high pain-related anxiety. Exp Brain Res. 2018 Apr 25; 1-12.

13. Villeneuve P, Parpay S. Examen clinique postural. Rev Podol. 1991; 59: 37-44.

14. Hirasawa Y. Study on human standing ability. Agressologie. 1973; 14(C): 37-44.

15. Cohen J. A Coefficient of Agreement for Nominal Scales. Educ Psychol Meas. 1960; 20(1): 37-46.

16. Landis JR, Koch GG. The Measurement of Observer Agreement for Categorical Data. Biometrics. 1977; 33(1): 159.

17. Nguyen $P, C$ remades $F$, Gatelet $C$. Test du maintien pelvien (TMP), degré de concordance. Neurophysiol Clin Neurophysiol. 2014; 44(1): 140-1.

18. Broise A-L, Geronimi M. Étude de la reproductibilité intra- et interpraticiens du test des chaînes stabilisatrices ou signe de Trendelenburg postural. Neurophysiol Clin Neurophysiol. 2012; 42(6): 390-1.

19. Blaszczyk JW, Prince F, Raiche $M$, Hébert R. Effect of ageing and vision on limb load asymmetry during quiet stance. J Biomech. 2000; 33(10): 1243-8.

20. Anker LC, Weerdesteyn V, van Nes IJW, Nienhuis B, Straatman H, Geurts $\mathrm{ACH}$. The relation between postural stability and weight distribution in healthy subjects. Gait Posture. 2008; 27(3): 471-7.

21. Winter DA, Prince F, Frank JS, Powell C, Zabjek KF. Unified theory regarding $\mathrm{A} / \mathrm{P}$ and $\mathrm{M} / \mathrm{L}$ balance in quiet stance. J Neurophysiol. 1996; 75(6): 233443.

22. Wang Z, Newell KM. Inter-foot coordination dynamics of quiet standing postures. Neurosci Biobehav Rev. 2014; 47: 194-202. 